Indonesian Journal of Cardiology

Indonesian J Cardiol 2020:41:54-58

pISSN: 0126-3773 / elSSN: 2620-4762 doi: $10.30701 /$ ijc. 1009

\title{
Primary PCI in COVID-19 Pandemic: Be Cautious, It Might Reveal Itself Later
}

\author{
Arief L Parama', Dmitri Rifanda', Wishnu A Widodo², Daniel Ruslim³
}

I General Practitioner, Jakarta Heart Center Hospital, Indonesia

2 Cardiologist, Jakarta Heart Center Hospital, Indonesia

3 Radiologist, Jakarta Heart

Center Hospital, Indonesia

Correspondence:

Arief L Parama

General Practitioner, Jakarta

Heart Center, Jakarta, Indonesia

E-mail: ariefparama@gmail.com

\begin{abstract}
Background: Acute ST-segment-elevation myocardial infarction (STEMI) is a disease of high mortality and morbidity, and primary percutaneous coronary intervention $(\mathrm{PPCl})$ is the preferred therapy for patient in golden period or with hemodynamic instability. ${ }^{1,2}$ Currently the world has been declared under COVID-19 (coronavirus disease 2019) pandemic by the World Health Organization (WHO).3 Signs and symptoms of COVID-19 patients can mimic acute decompensated heart failure, or induce acute cardiovascular problem. ${ }^{3}$ Screening is key, but there are conditions where physicians might miss positive COVID- 19 cases, especially in critical cardiovascular emergency.

Case Illustration: A 60-year old male came to emergency room with breathlessness and chest pain 8 hours prior. He was diagnosed as acute inferior STEMI with acute lung edema and cardiogenic shock (KILLIP IV, acute heart failure wet and cold). COVID-I 9 screening was negative. Patient underwent $\mathrm{PPCl}$, found to have total occlusion of right coronary artery (RCA) with thrombus and tight stenosis in left coronary artery (LAD). Successful PPCI to RCA was performed with TIMI 3 flow result, and hemodynamic improved. Ten hours after PPCl, hemodynamic deteriorated and peripheral oxygen saturation dropped. Patient was intubated and put on ventilator. Repeated chest X-Ray and thoracic CT showed lung condition has abruptly worsened - with ground glass opacity (GGO) found. His condition worsened quickly, and family agreed to a do not resuscitate (DNR) consent.

Conclusion: Acute cardiovascular condition in COVID- 19 Pandemics represent big challenges, especially in early diagnostic and cardiovascular intervention decision. We were presenting a case where signs and symptoms of COVID-19 might appear later. Therefore, in this pandemic era every emergency cardiovascular intervention with signs of respiratory problem should be performed as if patient was a positive COVID-19 case.
\end{abstract}

(Indonesian J Cardiol. 2020;41:54-58)

Keywords: STEMI, COVID-19, SARS-COV-2, PRIMARY PCI 


\section{Introduction}

A cute ST segment elevation myocardial infarction (STEMI) is a disease of high mortality and morbidity, and when the onset is less than 12 hours, primary percutaneous coronary intervention (PPCI) is the preferred therapy. ${ }^{1,2}$ Regardless of the time from symptoms onset, the presence of ongoing ischemic symptoms, life threatening arrhythmias, and haemodynamic instability is an indication for a PPCI strategy. ${ }^{1}$

On $30^{\text {th }}$ January 2020, WHO declared the outbreak of severe acute respiratory syndrome coronavirus 2 (SARS-CoV-2) a pandemic. ${ }^{3}$ Multiple reports showed that signs and symptoms of COVID-19 (the official disease name of SARS-COV-2 virus infection) patients can mimic acute heart problem such as acute decompensated heart failure, or induce acute cardiovascular problem. ${ }^{3}$

PPCI decision is dilemmatic in COVID-19 era, and if decided to be performed has to be made after a proper screening. In a suspected COVID-19 patient, thrombolytics should be preferred over PPCI, if possible. But in STEMI cases with hemodynamic instability or life threatening condition, the decision could mean life or death for the patient. In this situation, decision to perform emergency cardiovascular intervention will be challenged to the limit. ${ }^{4,5}$

\section{Case Illustration}

A 60-year old male patient came to our emergency unit with breathlessness and severe chest pain which started 8 hours before hospital admission. His heart rate was $55 \mathrm{bpm}$, blood pressure 100/60 $\mathrm{mmHg}$, with $88 \%-92 \%$ peripheral $\mathrm{O}_{2}$ saturation. Rales were found in in two - third of basal bilateral area of the lung. ECG showed sinus rhythm $55 \mathrm{bpm}$ with elevated ST segment in infero-posterior leads. He was diagnosed as acute infero-posterior STEMI with acute lung edema and cardiogenic shock (KILLIP IV, acute heart failure wet and cold). Patient denied any history of fever, cough, or flu-like symptoms beforehand and contacts with known suspected or confirmed COVID-19 patients. Thoracic $\mathrm{X}$-ray showed pulmonary vascular redistribution typical of lung edema without typical bilateral infiltrates.

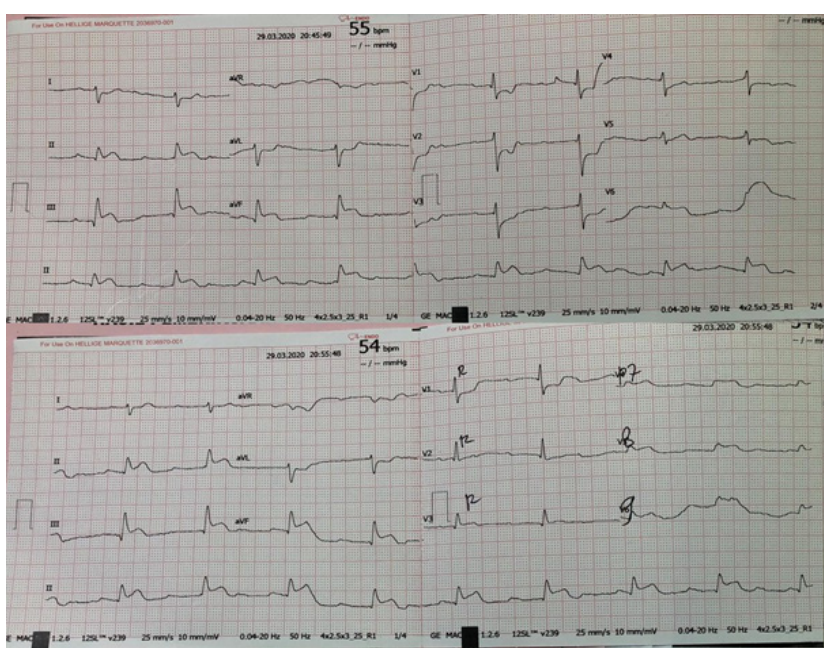

Figure 1. ECG showed first degree AV block with ST elevation in inferior and posterior leads (and reciprocal in anterior leads).

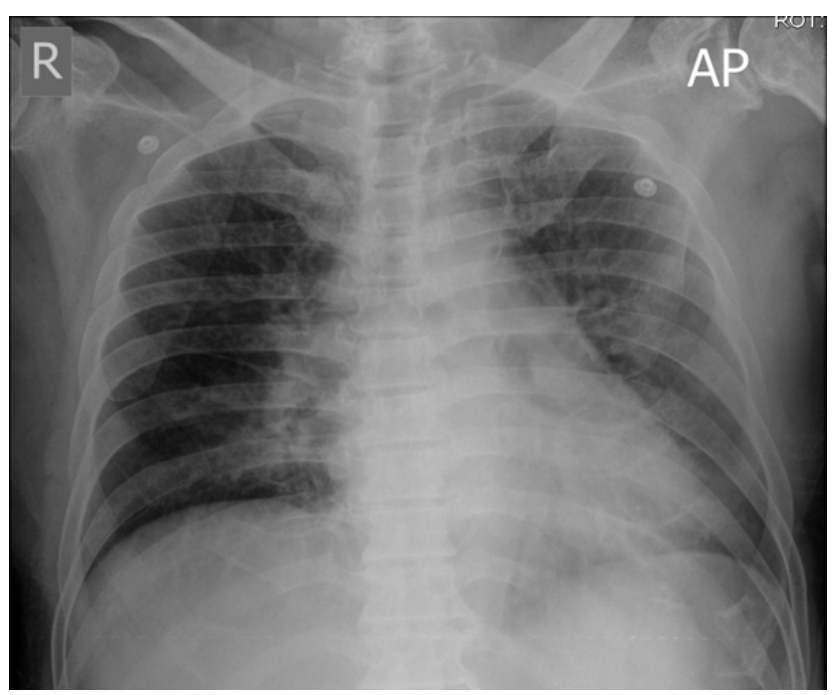

Figure 2. Thoracal X-Ray on admission shows pulmonary vascular redistribution typical of lung edema, but no typical peripheral bilateral consolidation.

PPCI was performed, and coronary angiography showed triple vessel disease with total occlusion in Right Coronary Artery (RCA) and 90\% stenosis of Left Anterior Descending (LAD) artery. One Drug Eluting Stent (DES) was successfully inserted in RCA with TIMI 3 flow result. Hemodynamic improved after the procedure, and patient moved to intensive care unit.

Ten hours after PPCI, patient condition deteriorated. Blood pressure down to $86 / 68 \mathrm{mmHg}$, heart rate increased to $110 \mathrm{bpm}$, and peripheral Oxygen 

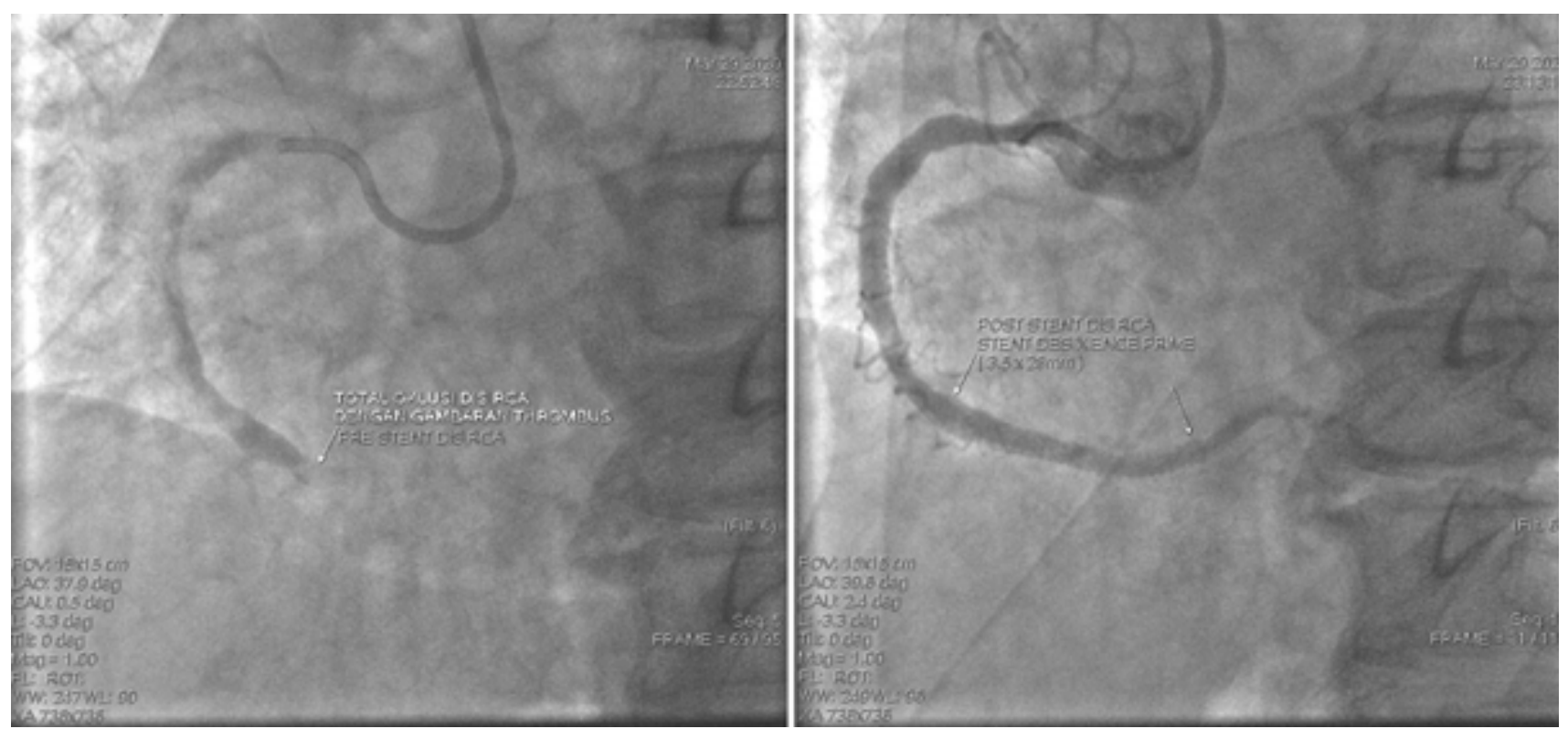

Figure 3. Culprit lesion in Right Coronary Artery (RCA). One Drug Eluting Stent (DES) was successfully deployed with final TIMI 3 flow result.

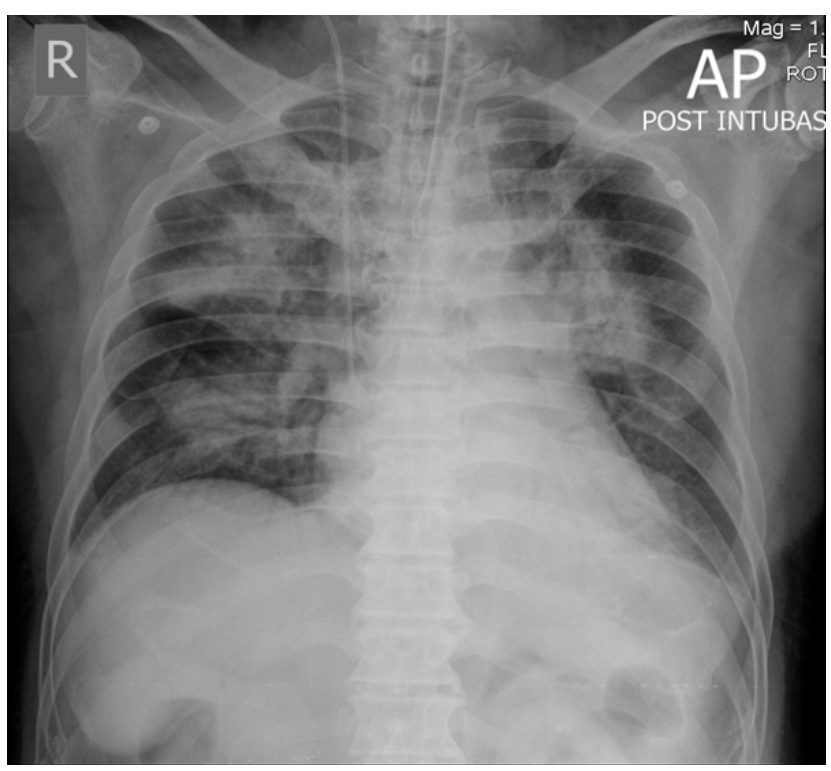

Figure 4. Repeated chest X-Ray showed diffuse infiltrate and peripheral consolidation in both sides of the lung.

saturation down to $85 \%$. Blood gas analysis showed severe respiratoric and metabolic acidosis. Patient were intubated. Repeated chest X-Ray showed diffuse infiltrate in both sides of the lung. Thorax CT Scan was performed, and typical ground glass opacity signs (GGO) were observed. Repeated differential count showed a low lymphocyte count of $3 \%$. Patient was assessed as a probable COVID-19 because of the typical chest X-Ray and CT Finding.

After 6 hours treated in ICU, having triple inotropic agents and mechanical ventilation supports, hemodynamic did not improved. Thorough explanation of the diagnosis and prognosis was delivered to the family, and they signed a consent for a do-not-resuscitate protocol. Patient did not survive.

\section{Discussion}

In patients with clinical suspicion of myocardial infarction with ST segment elevation, reperfusion therapy needs to be initiated as soon as possible. PPCI is the preferred strategy if the onset $<12$ hours or if hemodynamic condition unstable. Primary PCI is superior to fibrinolysis in reducing mortality, reinfarction, or stroke.1 However, in COVID-19 pandemics era, major cardiovascular society has modified their guidelines - SCAI (Society for Cardiovascular Angiography \& Interventions, U.S.A) and IHA (Indonesian Heart Association, Indonesia) has issued a modified algorithm which prefer fibrinolytic therapy over PPCI in patients with STEMI and COVID-19 suspect. ${ }^{4,5,6}$

Our hospital adopted these, especially IHA's 


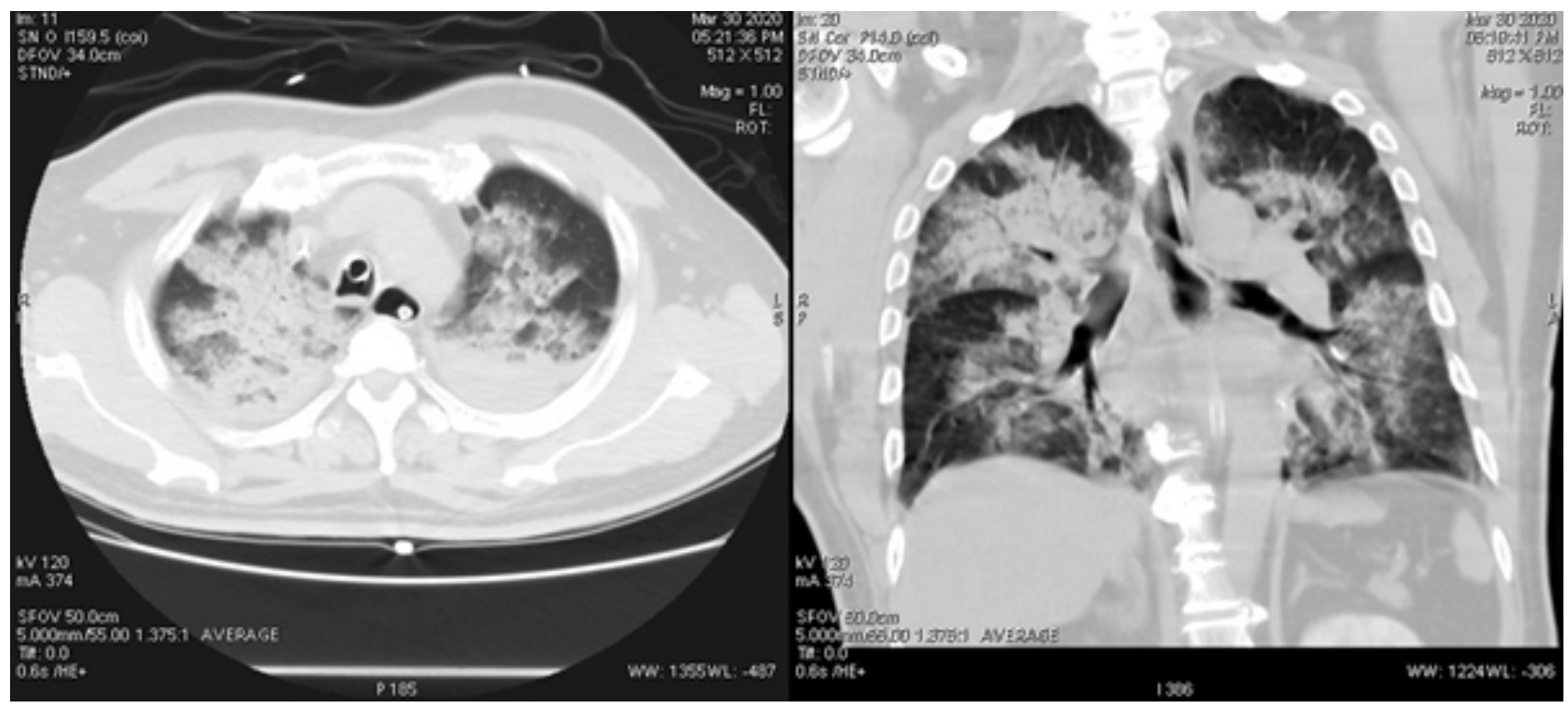

Figure 5. Typical ground glass opacity (GGO) signs were observed in Thoracic CT examination.

modified STEMI guidelines where all STEMI patients will be screened for possibility of infection. Negative patients should be treated according to standard STEMI guidelines. In patients under investigation or confirmed COVID-19 case, patients will be classified by the severity of pneumonia manifestation and hemodynamic condition. If the patient is in mild-moderate pneumonia and hemodynamically stable, fibrinolytic therapy is indicated over PCI. In hemodynamically unstable condition, patient will have PPCI in isolated catheterization laboratory, if the benefit overcome the risk. ${ }^{5,6}$

The problem with clinical criteria for COVID-19 in acute cardiovascular condition is that the signs and symptoms can be difficult to differentiate, or even overlapping. Before COVID-19 era, STEMI cases with respiratory problem, will be treated as STEMI with complication. In our patient, even when the lab and chest $\mathrm{x}$-ray was not indicating COVID-19, and there was a better explanation for the condition than COVID-19, signs and symptoms of severe pneumonia with typical COVID-19 appearance showed later. Swab test was failed to be performed on this patient, as the test kit for COVID-19 was heavily undersupplied at the time, in-house laboratory not trained yet, and a very long queue in official government lab. Diagnosis of COVID-19 suspect was made from CT-Scan and laboratory result. The positive and negative predictive value of chest CT for COVID-19 are estimated at 92\% and $42 \%$, respectively, moreover when the findings is a peripheral distribution of GGO, a distinctive COVID-19 marker. It is justified to say that thorax CT finding may not suitable as screening test for diagnosing COVID-19, but when the signs appear, is most likely confirmed to be one. ${ }^{7}$ Under WHO guideline, our patient is considered a suspected case as CT findings is sufficient to be evidence of COVID-19 infection case, whereas to be confirmed patients need to undergo RTPCR confirmation testing. All suspected case without testing or the result is inconclusive are considered to be a probable case, much as like our patient was. ${ }^{8}$

Worsening of the respiratory system, leading to acute respiratory distress syndrome (ARDS) and shock leads physicians to a high suspicion of SARS$\mathrm{CoV}-2$ infection in this pandemic era. Although highly probable, the exact cause of ARDS development cannot be pinpointed because RT-PCR was not available at that time. Reperfusion injury is one of the possibility of causing ARDS and rapid deterioration, causing the same cytokine storm just as in severe case of COVID-19. However, ARDS after PPCI is not a common case, at least not before COVID-19 Pandemics. And the prevalence of ARDS that caused by reperfusion injury is unknown. ${ }^{9,10}$

Cardiopulmonary resuscitation (CPR) in COVID-19 patient is also dilemmatic. When the 
prognosis is poor with heavy underlying condition, IHA has issued a modified version of their CPR criteria and algorithm. Whenever the patient has a poor prognosis and the risk of exposure to healthcare worker is high, it is possible to not perform CPR. A careful explanation and consent to the family has to be made prior to the decision. ${ }^{11}$

\section{Conclusion}

Acute cardiovascular condition in COVID-19 pandemics represent big challenges, especially in STEMI patients with unstable hemodynamic and respiratory problem. We were presenting a case where signs and symptoms of COVID-19 might appear later. Therefore every emergency cardiovascular intervention, especially the one with any signs of respiratory problem must be performed as if patient was a positive COVID-19 case. Many cardiac societies around the world have issued their modified algorithm about treatment of acute cardiovascular condition in COVID-19 era and should be adopted.

\section{References}

1. Ibanez B, James S, Agewall S, Antunes $M$, Bucciarelli-Ducci C, Bueno H et al. 2017 ESC Guidelines for the management of acute myocardial infarction in patients presenting with ST-segment elevation. European Heart Journal 2017;39(2):119177.

2. O'Gara P, Kushner F, Ascheim D, Casey D, Chung $\mathrm{M}$, de Lemos J et al. 2013 ACCF/AHA Guideline for the Management of ST-Elevation Myocardial Infarction. Circulation 2013;127(4):e362-e425.

3. Zheng Y, Ma Y, Zhang J, Xie X. COVID-19 and the cardiovascular system. Nature Reviews Cardiology 2020;17(5):259-260.

4. Szerlip M, Anwaruddin S, Aronow H, Cohen M, Daniels M, Dehghani P et al. Considerations for Cardiac Catheterization Laboratory Procedures During the COVID-19 Pandemic Perspectives from the Society for Cardiovascular Angiography and Interventions Emerging Leader Mentorship (SCAI ELM) Members and Graduates. Catheterization and Cardiovascular Interventions 2020.
5. Indonesian Heart Association. Panduan Praktik Klinis Perhimpunan Dokter Spesalis Kardiovaskular Indonesia: Stemi dengan Kecurigaan COVID-19. PERKI .2020. http://www.inaheart.org/upload/ image/PPK_STEMI_COVID_-_19_Last_Revise.pdf. Accessed April 18, 2020.

6. Burhan E, Santoso A, Nasution S, Ginanjar E, Pitoyo C, Susilo A et al. Protokol Tatalaksana COVID-19. 1st ed. Jakarta: PDPI, PERKI, PAPDI, PERDATIN, IDAI; 2020.

7. Simpson S, Kay F, Abbara S, Bhalla S, Chung J, Chung $\mathrm{M}$ et al. Radiological Society of North America Expert Consensus Statement on Reporting Chest CT Findings Related to COVID-19. Endorsed by the Society of Thoracic Radiology, the American College of Radiology, and RSNA. Radiology: Cardiothoracic Imaging 2020;2(2):e200152.

8. World Health Organization. Global surveillance for COVID-19 caused by human infection with COVID-19 virus: interim guidance, 20 March 2020. World Health Organization. https:/lapps. who.int/iris/handle/10665/331506. Accessed May 6, 2020.

9. Guzik TJ, Mohiddin SA, Dimarco A, Patel V, Savvatis K, Marelli-Berg FM et al. COVID-19 and the cardiovascular system: implications for risk assessment, diagnosis, and treatment options. Cardiovascular Research 2020.

10. Fröhlich GM, Meier P, White S, Yellon DM, Hausenloy DJ. Myocardial reperfusion injury: looking beyond primary PCI. European Heart Journal 2013;34(23):1714-1722.

11. Indonesian Heart Association. Pedoman Bantuan Hidup Dasar dan Bantuan Hidup Jantung Lanjut pada Dewasa, Anak, dan Neonatus Terduga/ Positif COVID-19. PERKI.2020. http://www.inaheart.org/ upload/image/Pedoman_BHD_dan_BHJL_pada_ COVID_19.pdf. Accessed April 18, 2020. 